Publicación semestral. ISSN 2215-4906

Volumen 81 - Número 1

Revista de las artes Julio - Diciembre 2021

\title{
Investigación artística en comunidades y colectivos de México y Centroamérica: estudios de casos
}

\author{
Susan Campos Fonseca \\ Adriana Raggi Lucio
}

DOI 10.15517/es.v81i1.47270

(c) (i) (8) Esta obra está bajo una licencia Creative Commons 
Editorial

\title{
Investigación artística en comunidades y colectivos de México y Centroamérica: estudios de casos
}

\author{
Susan Campos Fonseca ${ }^{1}$ \\ Universidad de Costa Rica \\ San José, Costa Rica \\ Adriana Raggi Lucio² \\ Universidad Nacional Autónoma de México \\ Ciudad de México, México
}

Los textos incluidos en este Dossier parten de ideas diversas sobre lo que hacer comunidad implica, desde el pensamiento situado de cada una de las personas autoras y sus prácticas artísticas. Sumamos diferentes voces y formas de enunciar; los textos aquí reunidos son un tejido y están vinculados por experiencias artísticas configuradas desde/junto con cada comunidad. Por una parte, estos textos son una forma de entender y acuerpar la dignidad existente en la propia forma de vivir; por otra, no constituyen una fórmula para justificar la producción de objetos cobijados por la validación de una estructura, cualquiera que esta sea.

Si bien algunas veces partimos de lugares similares y otras de lugares totalmente diferentes, lo que nos importa es compartir las vivencias reflexivas desde una diversidad de experiencias que en su conjunto nos permitan incorporar un hacer comunidad plural, que es a su vez una práctica pedagógica engendrada en/con/desde el medio educativo que la contiene. Consecuentemente, la investigación que dio como resultado los textos que reúne el dossier que editamos para este número, son entendidos desde la investigación artísti-

1 Musicóloga, compositora y profesora de la Escuela de Artes Musicales de la Universidad de Costa Rica (UCR). Doctora en música por la Universidad Autónoma de Madrid (UAM), especialista en estudios sonoros decoloniales y estudios transfeministas de la cultura y la tecnología. ORCID: 0000-0002-0645-0913. Correo electrónico: susan.campos_f@ucr.ac.cr

2 Artista visual, investigadora de la Facultad de Artes y Diseño de la Universidad Nacional Autónoma de México (UNAM). Coordinadora del grupo Mitote ICDAC. Doctora en Historia del arte por el Instituto de Investigaciones Estéticas de la UNAM. ORCID: 0000-0002-5832-8098. Correo electrónico: araggi@fad.unam.mx

ESCENA. Revista de las artes, 2021, Vol. 80, Núm. 3, pp.1-9 ISSN 2215-4906 
ca como forma y postura para construir actos pedagógicos de resistencia afectiva, que funjan como posibilitadores y detonantes en la construcción de la idea de un ambiente de saberes y conocimientos comunitarios, que esté ubicado desde la experiencia del sujeto situado y a partir del cual puedan generarse discusiones sobre las distintas metodologías y estrategias empleadas.

Con este propósito, identificamos y convocamos a personas que trabajan en esta construcción, con quienes celebramos reuniones abiertas donde compartimos las experiencias con comunidades y colectivos en México y Centroamérica. Estas reuniones se realizaron vía plataforma Zoom los días 5, 12 y 26 de junio, y el 3 de julio de 2020. El 5 de junio abrimos las sesiones con una invitada especial, la artista costarricense Rossella Matamoros Jiménez (n. 1960), quien ofreció su experiencia con la conferencia "Trauma y recuperación", cuyo registro en video sumamos a esta publicación.

Rossella Matamoros compartió algunos de los objetivos, metodologías y resultados de actividades de trabajo comunitario que realizó entre 1998 y 2019. Las actividades diseñadas por Matamoros se basan en un diseño transversal, cuyo propósito es construir ecologías de saberes entre las personas que participan en los talleres organizados por ella, sumando los conocimientos que puede compartir desde su formación como artista. Matamoros entiende el "arte como práctica social" y concluye que:

La pandemia ha sido un espejo y una pregunta acerca de quiénes somos como sociedad, y las repercusiones de lo que hemos hecho con nosotros mismos y el planeta. Creo que el único camino es dar, solidariamente dar contenido y herramientas, porque los sistemas sociales (barrios en Costa Rica, colonias en México), tienen que reconstruirse desde adentro. Nosotros no podemos hacer cambios estructurales, pero sí abogar por los derechos y servicios para todos ... Las personas están acostumbradas al trauma, a la violencia, a que les quiten algo. Los talleres que diseño pueden ser un espacio seguro. ${ }^{3}$

La trayectoria de Rossella Matamoros es un antecedente importante para la actividad de apoyo a la investigación C0766 "Investigación artística implicada con comunidades y colectivos Mesoamericanos: estudio de casos" (2020-2021), inscrita en el Instituto de Investigaciones en Arte (IIArte) de la Universidad de Costa Rica, cuyos resultados reúne este

3 Se anexa a este número la grabación de la conferencia que Rossella Matamoros compartió con nosotros el 5 de junio de 2020. 
número4. Esto justifica la elección de su obra "Indicios (Signs)" como portada. La obra pertenece a la serie La herida más luminosa, realizada por la artista a consecuencia del atentado del 11 de septiembre de 2001 en la ciudad de Nueva York (EEUU). Esta obra coincide con su propuesta de una práctica artística en comunidad, hecha desde el trauma y en busca de la sanación.

Puede afirmarse, entonces, que la investigación artística implicada con comunidades y colectivos de la que dan muestra los casos de estudio reunidos en este dossier es sostenida por la idea de una crítica pedagógica que nos permite recorrer un camino prometedor desde lo afectivo, que promueva el análisis constante de las estrategias de análisis crítico para pensar lo comunitario en los ambientes académicos, pero sobre todo que posibilite la construcción de un pensamiento consciente y situado sobre lo que, desde nuestro hacer, puede afectar/afectarse en términos del derecho a construir metodologías propias y diversas en/desde/con las comunidades y colectivos no-académicos. Se evidencia así la coincidencia de epistemologías desobedientes, aunque no todos los trabajos comparten este marco teórico.

Compartimos en lugares como el aula, el patio o la calle, nuestra inventiva y las formas de nuestra narración, porque hemos observado que muchas veces no sabemos de manera precisa qué quiere decir el término decolonial para la academia. Aunque fue justo en estos lugares donde fue inventado por elección de algunos que pusieron en esa discusión su mirada y su hacer y, por ello, procurando convertirlo en "escuela de pensamiento". Pero, con la misma potestad electiva que nosotros(as) empezamos a deshacernos de las ideas que enmascaran la normalización de métodos alienantes, patriarcales, disociativos razón-emoción, jerárquicos y heteronormados, que la colonialidad ha diseñado con tanta eficacia, peregrinamos decolonizarnos, para vernos de afuera hacia dentro y al revés.

Este número reúne textos de Mitote ICDAC, un grupo de investigación que trabaja desde diferentes puntos de vista la educación artística y diseñística en la Facultad de Artes y Diseño de la Universidad Nacional Autónoma de México5 ${ }^{5}$ y artículos de personas

4 Esta actividad de apoyo a la investigación tiene a Susan Campos Fonseca como investigadora principal, y a Adriana Raggi Lucio como investigadora colaboradora.

5 El Mitote ICDAC es un grupo de investigación de la Facultad de Artes y Diseño de la UNAM, que trabaja sobre educación artística y su relación con la investigación artística y las comunidades de aprendizaje. Consultar: https://mitote.org

ESCENA. Revista de las artes, 2021, Vol. 81, Núm. 1 (julio-diciembre), pp. 1-9 
invitadas que desarrollan actividades afines en México, Costa Rica y Panamá. Los artículos del grupo Mitote ICDAC son: "Pensar a Simón Rodríguez desde las prácticas artísticas: La indisciplina como una forma de resistencia afectiva" de Rubén Cerrillo; "Entrelazando caminos. La experiencia como elemento colaborativo de la investigación artística al hacer comunidad" de Jarumi Dávila; "Entre hilos, lienzos y memorias lacustres. Taller de textiles FARO Tláhuac" de Erika Karina Jiménez Flores; "Pensar la educación desde la colaboración. El Mitote como un trabajo colectivo" de Adriana Raggi Lucio y María de Guadalupe Sánchez Estrada; "Territorio y andar, des-bordamientos de la práctica artística desde el desplazamiento de las comunidades indígenas" de Carlos Romualdo, y "Contenedor de voces desde la narrativa propia frente a los discursos dominantes en la educación artística" de María del Carmen Rossette Ramírez.

Algunos textos tejidos en la sección de Artículos son la prueba de que aquellas búsquedas pueden generar otras narrativas en un aula, sobre todo aquellas que invitan a desbordarla. Así lo vemos en el texto de Raggi y Sánchez, donde se muestra cómo es que los desplazamientos comunitarios a través de la escucha humilde y desinteresada pueden articular metodologías tan frescas como los Mitotes de colaboración y exploración sobre la educación artística desde Simón Rodríguez, Juan Acha y Melquiades Herrera, los cuales fueron una experiencia académica desjerarquizada del grupo de Investigación Mitote ICDAC. Esta metodología surgió del concepto de Mitote: fiesta colectiva para el convivio, de la charla cercana y de la gratitud por la escucha desinteresada; de ese modo, permitió que el compartir saberes se generara a través de lo común para poder hablar desde nuestras experiencias.

Estas prácticas posibilitan mirar los saberes desde una perspectiva que emancipa su potencia desde la noción de resistir con alegría, ya que generar actos educativos desde la escucha humilde es una propuesta pedagógica que nos ha desplazado del pensamiento jerárquico educativo a uno mucho más comunitario y horizontal que, entre otras cosas, se despoja de las máscaras de control e imposición dogmática para permitirnos pensarnos desde otro lugar y con otras voces (hemos acuerpado este proceder llamándolo acompañamiento educativo). Así, la charla partió de nosotros(as) y los(as) otros(as): Simón Rodríguez, Juan Acha, Melquiades Herrera y la artista trans Lía García, todos(as) juntos en un mitote que integró tiempos, geografías y perspectivas diversas. 
Investigación artística en comunidades y colectivos

Editorial de México y Centroamérica: estudios de casos

De ahí nos tejemos, por vía de los afectos epistémicos, hacia nuestras raíces des-obedientes, para construir genealogías de resistencia disidente y proactiva. Es así como, a partir del texto de Cerrillo, nos encontramos con la figura de Simón Rodríguez (Caracas, 28 de octubre de 1769- Amotape, 28 de febrero de 1854), quien desde sus desafiantes páginas nos invita a ver en compañía de sus ojos y sus letras indisciplinados. Este artículo parte de la indisciplina y se desarrolla desde ella como una forma de poner sobre la mesa el papel de la dignidad epistémica, de auto-representación y de narrativa que los miembros de las comunidades educativas debieran tener, como piso mínimo, para ejercer la elección articulatoria de sus saberes como una forma de ejercer esa dignidad. Esto nos vincula con lo dicho por Jarumi Dávila, quien piensa nuestros tejidos como acciones que se desplazan al aula para detonar reflexiones situadas y nos hacen, como siguiendo la puntada en el bordado, reencontrarnos con la idea de que habitar el espacio educativo como una forma de estar en el mundo es uno de los actos más significativos que podemos encontrar, si logramos verlo con ojos indisciplinados y desbordados. Finalmente, en el texto "Territorio y andar, des-bordamientos de la práctica artística desde el desplazamiento de las comunidades indígenas", Carlos Romualdo analiza su experiencia en el desplazamiento y migración de la comunidad Mazahua/Jñatrjo originaria del Estado de México, hacia la Ciudad de México, para tejerla con su trabajo educativo y el conflicto que vive en los contextos que conforman al autor, que son su práctica artística y su relación comunitaria indígena.

De ese modo, nuestros hilos narrativos construyen una trama donde nuestros textos habitan un espacio propicio para un tipo de desobediencia que cuestiona, de manera crítica, la idea monolítica sobre la esencia jerárquica de la educación construida a través de una complicada parafernalia que la marca como única e incuestionable. Los textos del Mitote ICDAC buscan narrar nuestras historias y acuerpar la idea de que otras narrativas son posibles y que esa es una forma digna de construir sentido desde nuestro hacer.

A esta sección de artículos se suman los textos de personas invitadas que no pertenecen al grupo Mitote ICDAC, pero que participaron en las sesiones que organizamos. Resultado de esta colaboración son: "Híbridas y Quimeras: Ruido y sororidad colectiva en la Ciudad de México" de Ana Mora, quien también estudia un caso situado en México, documentando el trabajo colaborativo entre artistas sonoras en el contexto urbano. Mora estudia cómo la "sororidad" construye epistemología acerca de la creación experimental en busca de espacios seguros e inclusivos. Entre Ciudad de México y Ciudad de Panamá, la investigación artística a partir de prácticas sonoras confluye en el trabajo de Mar Alzamora Rivera,

ESCENA. Revista de las artes, 2021, Vol. 81, Núm. 1 (julio-diciembre), pp. 1-9 
quien colabora con su artículo "Songlines - Las caminatas sonoras como espacio para la memoria: El tranvía de la Ciudad de Panamá". Alzamora Rivera comparte los resultados de su investigación artística dedicada a cómo se entretejen la ciudad, el sonido y la memoria, utilizando como metodología las "caminatas sonoras".

La sección concluye con el trabajo de la bailarina costarricense Verónica Monestel, quien colabora con un análisis de los proyectos de acción social de la Compañía Danza Universitaria de la Universidad de Costa Rica, en su artículo "COMUNIDANZA II: análisis en torno a la práctica artística entre danza, comunidades y acción social". El texto tiene como objetivo visibilizar, analizar y re-conceptualizar la acción social a partir de las prácticas artísticas comunitarias realizadas por la agrupación entre los años 2011 y 2019. Monestel propone una escucha anticipada de carácter lúdico y creativo, centrada en la acción, la construcción de nuevas metodologías de mediación y el desarrollo comunitario inclusivo y descentralizado. Los vínculos en la acción comunitaria, el cuerpo, la naturaleza interactiva de la danza y su componente educativo se identifican como ejes fundacionales implícitos en su práctica.

Finalmente, por indicación de la dirección de ESCENA. Revista de las Artes, se incluyen en la sección denominada Reflexiones, los tres textos de Erika Jiménez, Carmen Rossette y Luis Fernando Quirós. En "Entre hilos, lienzos y memorias lacustres. Taller de textiles FARO Tláhuac", Erika Jiménez teje su narrativa desde la memoria y la vivencia en comunidades afectivas. La autora evidencia una ciudad que enmarca y contiene una gran crueldad, al mismo tiempo que sostiene un peregrinaje de perpetua búsqueda y de resistencia narrada desde lenguas indígenas que se pierden y se recuperan, que se sostienen con el esfuerzo de sus cuidadores y entonces, a veces sin merecerlo, nos sostienen.

De ahí se traza con puntadas imperfectas una línea al texto "Contenedor de voces desde la narrativa propia frente a los discursos dominantes en la educación artística" de Carmen Rossette. Desde la FARO de Jiménez a la FARO de Rossette, encontramos una experiencia educativa que en el hacer de sus prácticas cuestiona lo colonial: la implicación viva de lo que la periferización de la FARO ha significado para quienes han construido vida y prácticas artísticas desde esa comunidad tan particular que, desde la voz de su día a día, construyen una línea crítica hacia la educación formal institucionalizada. De tal manera, Rossette, con su habitar en esos dos territorios, conecta una línea hacia la Facultad de Artes y Diseño de la Universidad Autónoma de México. En la educación formal de la academia, las puntadas tienen ritmos discontinuos y en tensión constante, desde ahí se construyen 
Investigación artística en comunidades y colectivos

Editorial de México y Centroamérica: estudios de casos

resistencias que a veces parecen no ser tan evidentes, pero que, de una u otra forma, existen y se mantienen potentes.

El reportaje del artista costarricense Luis Fernando Quirós, "Mesoamérica, Tierra, Maíz, Agua", propone revisar las prácticas artísticas mesoamericanas y otros caracteres de identidad de la cultura ancestral, con la idea de aunar un colectivo que trabaje con los elementos origen del planeta, entre otros, tierra y agua. Intenta identificar creadores(as) que elaboran su práctica artística a partir de ambos elementos, sea a través de la materia física, tangible, el suelo, pero también intangible, abordado a través de simbolismos y narrativas que trascienden desde los orígenes del mundo y, en particular, la zona de Mesoamérica.

Como resultado de la actividad de apoyo a la investigación C0766 "Investigación artística implicada con comunidades y colectivos Mesoamericanos: estudio de casos" (20202021), inscrita en el IIArte, este dossier demuestra cómo para la universidad el régimen neoliberal de indexaciones y rankings académicos se convierte en una justificación para imponer la colonialidad del saber, especialmente para quienes entienden como conocimiento legítimo solo aquel validado por sus marcos teóricos, metodológicos, teleológicos, genealogías y un largo etcétera. El objetivo de abrir un diálogo implicado entre la universidad y los saberes comunitarios tuvo que confrontar la imposición de los argumentos de la indexación y los rankings. Esto debe denunciarse. La división entre artículos y "Reflexiones" en este número se debió a esta imposición, que se sustenta en que una investigación solo es académica y científica en la medida en que remite a "voces expertas", entendidas estas como "académicas", excluyendo la experticia de las personas de las comunidades y sus saberes. Pero no solamente la idea de "voces expertas" parte de la división entre academia y saberes comunitarios, también genera una exclusión de voces académicas que trabajan desde la desobediencia epistémica y otras formas de generación de saberes, como la comunidad que se crea en un espacio educativo. Cuando pensamos las voces expertas como unas cuantas voces reconocidas, parcelamos el saber y detenemos procesos emancipatorios, lo que permite que erremos el camino, en lugar de inventar una realidad afectiva alejada de la violencia y de la imposición. ESCENA. Revista de las Artes nos explicó que "Reflexiones" está pensada como un espacio que la revista abre con el propósito de solventar esta situación, de la cual son conscientes.

En términos generales, las experiencias reunidas por los textos de las personas que generosamente colaboraron en este tejido, demuestran que el ejercicio de escritura y análisis sistemático de experiencias de investigación artística, en los términos planteados

ESCENA. Revista de las artes, 2021, Vol. 81, Núm. 1 (julio-diciembre), pp. 1-9 
por el proyecto que da como resultado este dossier, es un proceso vivo. Desde las prácticas artísticas y las comunidades de aprendizaje que nos revelan estos textos, podemos pensar la investigación artística como procesos y metodologías que se comparten junto/desde las comunidades.

Para finalizar, en las reuniones previas participaron más personas que las que aparecen aquí, pero para algunas de ellas el proceso de redacción y argumentación científica requerido para participar en la publicación final resultó ser un reto y un requisito difícil de resolver, evidenciando incompatibilidades entre modos de hacer y pensar, aspecto que fue considerado, concluyendo que no se resolvía sumando obra artística al "dossier", ya que el ejercicio primario era analizar en qué medida es posible una investigación en los términos planteados por el proyecto que anima este dossier. No obstante, en su selección de textos, esta edición procura ser flexible para cumplir con el propósito de documentar metodologías y epistemologías diversas, forjadas entre personas, comunidades, colectivos no-académicos y la universidad. 